This item was submitted to Loughborough's Research Repository by the author.

Items in Figshare are protected by copyright, with all rights reserved, unless otherwise indicated.

\title{
A novel "resilience viewpoint" to aid in engineering resilience in systems of systems (SoS)
}

PLEASE CITE THE PUBLISHED VERSION

https://www.incose.org/symp2018

PUBLISHER

INCOSE @ Demetrios Joannou

VERSION

AM (Accepted Manuscript)

\section{PUBLISHER STATEMENT}

This work is made available according to the conditions of the Creative Commons Attribution-NonCommercialNoDerivatives 4.0 International (CC BY-NC-ND 4.0) licence. Full details of this licence are available at: https://creativecommons.org/licenses/by-nc-nd/4.0/

\section{LICENCE}

CC BY-NC-ND 4.0

\section{REPOSITORY RECORD}

Joannou, Demetrios, and Roy S. Kalawsky. 2019. "A Novel "resilience Viewpoint" to Aid in Engineering Resilience in Systems of Systems (sos)". figshare. https://hdl.handle.net/2134/33912. 


\title{
A Novel "Resilience Viewpoint" to aid in Engineering Resilience in Systems of Systems (SoS)
}

\author{
Demetrios Joannou \\ Loughborough University, UK \\ +44 (0) 1509635674 \\ d.joannou@,1boro.ac.uk
}

\author{
Roy Kalawsky \\ Loughborough University, UK \\ +44 (0) 1509635678 \\ r.s.kalawsky@,1boro.ac.uk
}

Copyright $\odot 2018$ by Demetrios Joannou. Published and used by INCOSE with permission.

\begin{abstract}
Designing evolutionary systems to meet stakeholder expectations on safety, reliability and overall resilience is of great importance in an age of interconnectivity and high dependency systems. With incidents and disruptions becoming more frequent in recent years, the requirement for systems to demonstrate high levels of resilience given the economic, political and temporal dimensions of complexity, resilience is of great significance today. Systemic resilience is of high importance at the global level. Therefore, the role of the system engineer and architect is becoming more demanding due to the need to consider requirements from a broader range of stakeholders and to implement them into early conceptual designs. The early modeling process of all systems is common ground for most engineering projects, creating an architecture to both understand a system and to design future iterations by applying model-based processes has become the norm. With the concept of systems-ofsystems (SoS) becoming common language across multiple engineering domains, model-based systems engineering techniques are evolving hand-in-hand to provide a paradigm to better analyse current and future SoS. The intrinsic characteristics of the constituent systems that make up the SoS make the challenge of designing and maintaining the reliability and resilience of a systems extremely difficult. This paper proposes a novel viewpoint, within an architecture framework (based around DoDAF, MoDAF and UPDM) to aid systems architects explore and design resilient SoS. This is known as the Resilience Viewpoint. Much of the research in the area is focussed on critical infrastructure (CI), looking at telecommunication networks, electric grid, supply networks etc, and little has been done on a generalizable tool for SoS architecture analysis, especially using existing modeling languages. Here, the application of the 'Resilience Viewpoint' is demonstrated using a case study from an integrated water supply system of systems, to portray its potential analytical capabilities.
\end{abstract}

\section{Introduction}

Resilience engineering (Christopher P. Nemeth, 2014; Hollnagel, Paries, Woods, \& Wreathall, 2011; Madni \& Jackson, 2009) and the role of extending risk management strategies into projects have introduced some stimulating changes to the discipline of systems engineering (Stillitto, 2015). While systems engineering has always included processes to analyse risk in engineered projects, the notion of resilience has added new dimensions in the challenges of engineering reliable and resilient systems and services. Despite the lack of a common definition for the term resilience in the general sense, there is consensus that it is broadly related to the properties which are defined in the Oxford Dictionary of English as an object and its "ability to recoil or spring back into shape after bending, stretching, or being compressed"(Oxford Dictionary of English, 2010). Due to the lack of a resilience definition with regards to SoS, there have been a range of frameworks adopted to assess the resilience from both qualitative and quantitative approaches (Erol \& Sauser, 2009; Filippini \& Silva, 2014; Rahimi \& Madni, 2014). However no standardized approach exists, thus, a void remains to analyse systems of most classifications because of the immaturity of tools which lack their own adaptability, 
flexibility and utility (Rahimi \& Madni, 2014). For the purpose of this paper, a definition has been provided for resilience in the context of SoS:

"The overall dynamic ability of the SoS to adapt in times of change and disruption at both the SoS and constituent system level, and to continue to provide operational functionality at a desired level of functionality."

As an evolving engineering topic (Hosseini, Barker, \& Ramirez-Marquez, 2016; Uday \& Marais, 2014), resilience engineering is relatively unique and moderately young with regards to more established engineering disciplines. The theme of engineering resilience is particularly important in the context of systems-of-systems (SoS), a classification of system that has become the norm in today's interconnected world. Systems of this nature include; air transport systems (ATS), emergency response systems, cyber-security systems, military systems, water resource management and distribution, and so on. These super-systems see a collection of previously perceived; 'independent systems' collaborating at a higher-level and exhibit operational capabilities and emergent behaviours (Karcanias and Hessami, 2011) that cannot be exhibited from the individual systems i.e. emergence (A. G. Hessami, 2011; A. Hessami \& Karcanias, 2010) . The innate operational, managerial independence, evolutionary development and geographic distribution characteristics associated with the constituent systems, presents difficult challenges for sustaining a reliable and resilient SoS.

Developing analytical tools to support the analysis of SoS is not easy, especially since SoS do not follow the conventional definition of systems and pose great challenges which are discussed at length in this paper. Technical support for systems engineers to analyse SoS should provide a systematic view of the overall SoS and its constituent systems (CS), mapping out stakeholders and CS, and outlining operational aspects and functional aspects of all constituent elements. A magnitude of dependencies exists between the aggregation of components within a SoS, and it is within these interrelationships at the operational level, that the features of resilience, reside. The proposed resilience viewpoint will provide the systems engineer or architect with a set of additional benefits beyond what the current modeling tools offer [(Mohammad, Kaminskiy, \& Krivtsov, 2010)] which are specific to a given domain. Whereas the resilience viewpoint and the additional architecture viewpoints will give a holistic view of the SoS and a set of models/views that give a definitive focus on the resilience aspects of SoS design.

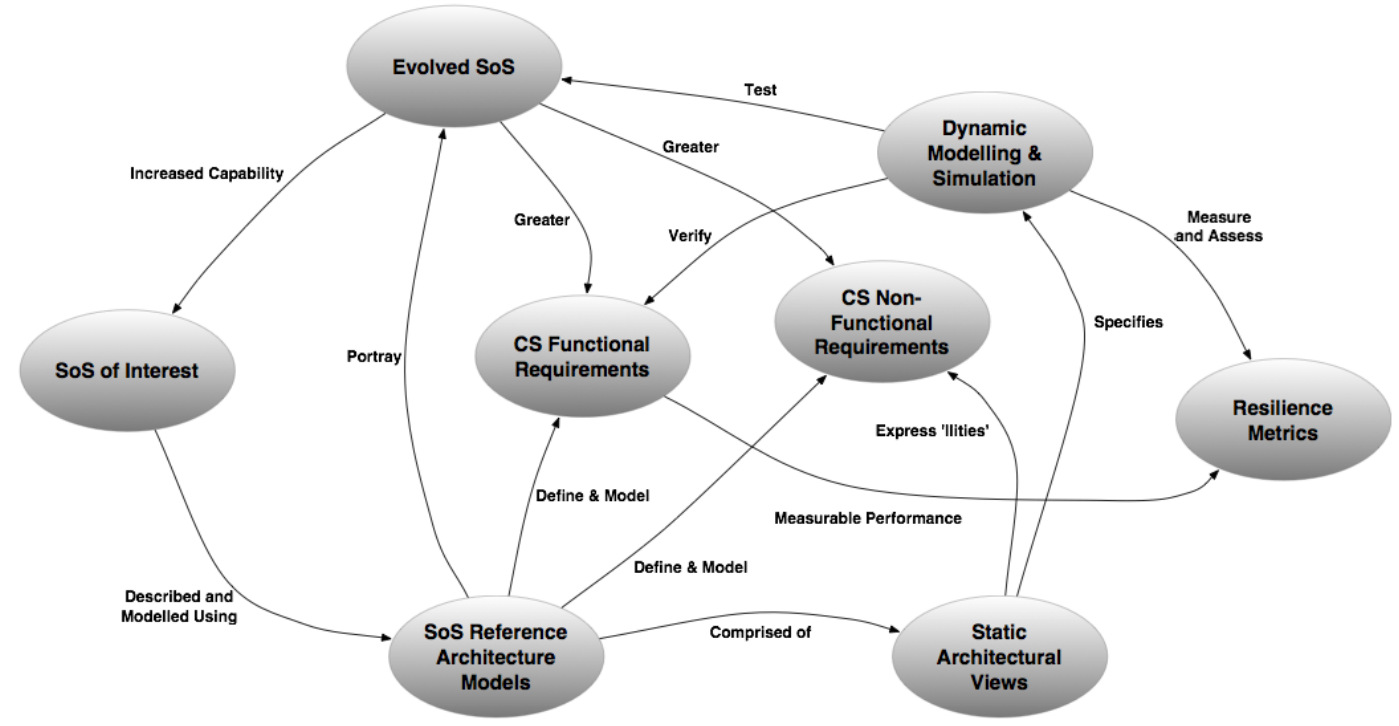

Figure 1. Evolving an SoS through MBSE processes

The diagram in Figure 1 shows that the SoS must be modelled in terms of the functional and nonfunctional ('ilities') properties, which ultimately provide the resilience features in the SoS. Having a SoS architecture with a series of models allows the engineer or architect to express the SoS and its 
CS from a range of perspectives through a range of architectural viewpoints within an architecture framework (Hause, 2010a; Hayden \& Jeffries, 2012; Urbaczewski \& Mrdalj, 2006). These static, architectural representations go a long way in the conceptual phases of design, allowing effective communication with stakeholders who have an influence on shaping the CS and the requirements definition process for future phases of the SoS evolution. Furthermore, as the diagram suggests, some form of dynamic modeling and simulation is required to test the performance metrics of conceptual models and the functional requirements of the CS. The resilience of a system will be measured in terms of meeting those performance requirements and demonstrating certain ilities (Table 1) that will allow the SoS to cope in times of disruption and irregular events.

\section{Systems of systems and Resilience}

Typically, a SoS (Maier, 1996) will incrementally evolve over several years or decades (Figure 2), to provide increased capability through the integration, addition, substitution, or removal of its CS. Unfortunately, traditional systems engineering methods, process and tools (Friedenthal, Moore, \& Steiner, 2014; Ibarra-zannatha et al., 1994) do not accommodate the design and development of the aforementioned actions in the design of SoS evolutions with regards to its CS. The lack of an overall SoS 'manager' insinuates additional complexities in SoS design, especially with regards to resilience as the introduction of emergent behaviours are prone as new interactions transpire. It is not suggested that an SoS manager is feasible, however the role of such stakeholder would align CS goals and influence decisions to achieve the overall SoS goals. This role could be led by a CS within the SoS or a government organisation, depending of the SoS type. Challenges posed by the SoS with regards to the overall resilience are investigated in this paper and work on a novel resilience viewpoint within an existing architecture framework (the Department of Defense Architecture Framework, DoDAF (Hause, 2010a)) for engineering resilience in SoS is proposed. This process is part of a larger framework that includes several integrated processes to provide insights into architecture exploration for SoS design and evolution. Specifically, designing resilience in SoS.

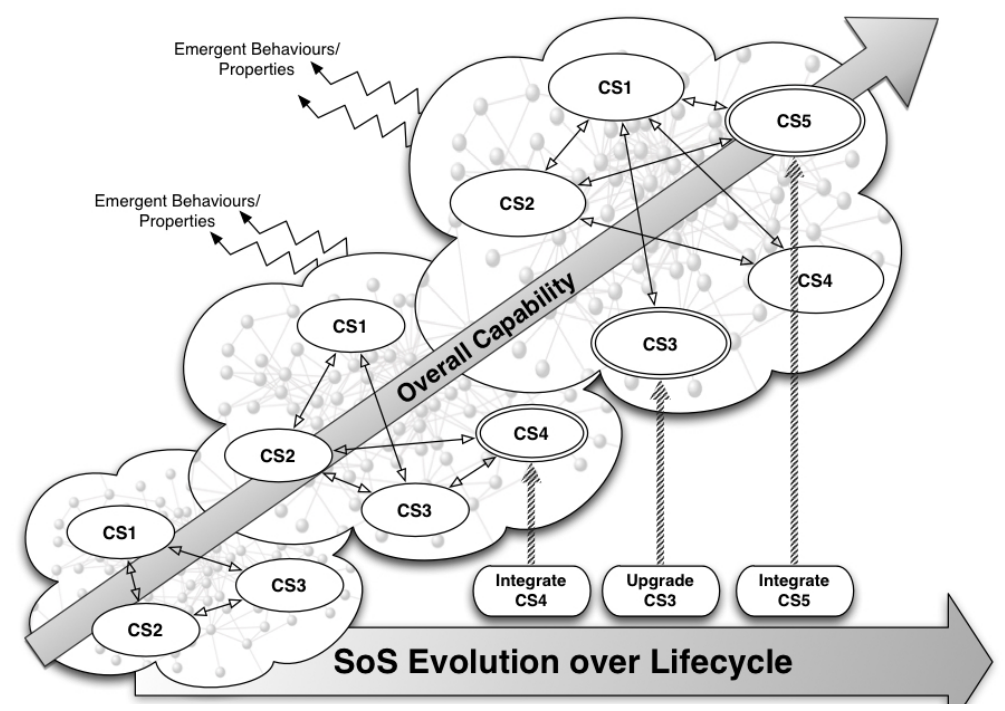

Figure 2. The Evolving SoS

The concept of resilience has generated great momentum in the realm of engineering resilience in complex systems and SoS (Bergström, Winsen, \& Henriqson, 2015; Bernice Lee, Felix Preston, \& Gemma Green, 2012; Labaka, Hernantes, \& Sarriegi, 2015), and surpasses the discussions of traditional engineering methods for reliability, robustness, security, risk management, and so forth. The proposed resilience viewpoint will add value and insight for systems engineers, architects and other practitioners who are analysing large mega-systems like SoS. As part of the reference architecture, the viewpoint is thought to add value in evaluating the structural resilience of the SoS topology focussing on a collection of systems with respects to vulnerability and criticality to an 
anticipated disturbance. Furthermore, the viewpoint allows for the non-functional properties (the 'ilities' (McManus, Richards, Ross, \& Hastings, 2007)) to be explored and assigned to parts of the architecture that deliver functionality.

Table 1: Definition of Ilities

\begin{tabular}{|l|l|}
\hline \multicolumn{1}{|c|}{ 'Ility' } & \multicolumn{1}{c|}{ Definition } \\
\hline Adaptability & $\begin{array}{l}\text { The ability of a system to change or be changed and to adjust readily to different } \\
\text { conditions }\end{array}$ \\
\hline Evolvability & $\begin{array}{l}\text { The ability of a CS or SoS design to be changed over time to generate new } \\
\text { capabilities }\end{array}$ \\
\hline Robustness & $\begin{array}{l}\text { The ability of a SoS or CS to maintain specific parameters in the context of } \\
\text { changing system internal and external forces }\end{array}$ \\
\hline Flexibility & The ability of a system to change when presented with external forces \\
\hline Changeability & $\begin{array}{l}\text { The ability of a CS to change its form at an acceptable level of resource } \\
\text { expenditure and thus its function to continue operating }\end{array}$ \\
\hline Reparability & The ability of a system to 'fix' itself after an incident of disruption \\
\hline Scalability & The ability of a CS to change the current set of definite system parameters \\
\hline Versatility & The ability to satisfy diverse requirements without changing current form \\
\hline Availability & $\begin{array}{l}\text { The ability of a system to be utilised for a specific capability or performance } \\
\text { requirement }\end{array}$ \\
\hline
\end{tabular}

Resilience should be considered at the architectural design phase of development, implying there must be some trade-off between increasing levels of resilience and cost of implementation. This paper proposes a guide similar to the levels of automation taxonomy proposed by Sheridan and Verplank (Hou, Banbury, \& Burns, 2014), a similar idea can be construed for increasing levels of resilience in SoS. Figure 3 outlines this idea and demonstrates zero to five levels of resilience. Level zero implies no resilience present and five being "fully" resilient. There is an evident relationship between levels of resilience and likelihood of failure (Ash \& Newth, 2007). High resilience insinuates low levels of vulnerability and vice versa for low levels of resilience. Resilience, of course, comes at a monetary cost. Higher levels of resilience are costlier as fail-safe mechanisms are built into the systems, and redundancy measures are heavily implemented to mitigate against freak incidents or unforeseen circumstances. It is difficult to allocate a quantitative value i.e. cost, to each level of resilience at this stage, as it will be relative to the context of the SoS the CS under analysis in a given scenario.

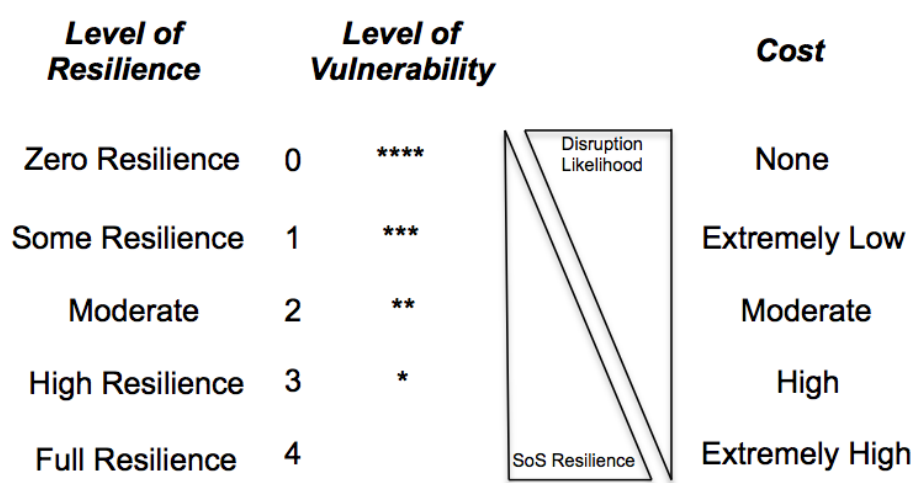

Figure 3. SoS Levels of Resilience 
A simple example of this would be to consider the delivery of fresh water to a demand centre in a region of frequent earthquakes. In order to reduce the likelihood water being cut off to that demand point due to a pipe burst, additional pipelines could be installed as backup water delivery mechanisms. This will obviously cost more money; however, the dire consequences of water shortage are more like to be averted. Figures 4 and 5 show a network of demand centres supplied with water from a service reservoir where water is supplied to the water grid and delivered via mains supply pipes to demand centres. Figure 4 shows one mains pipeline, whereas Figure 5 shows dual supply. Figure 5 clearly shows an increased level of resilience as the demand centres become less vulnerable to a water cut-off and sustained availability of water is likely in the incident of one of the mains pipes breaking. Although this is a simple example, it shows the architectural implications of resilience in a clear way. The non-functional properties that have been addressed in this specific examples are availability, flexibility, robustness and if the water regulators choose to switch between the two delivery pipes in times of operation, it gives them a degree of adaptability (Nelson, Adger, \& Brown, 2007), also.

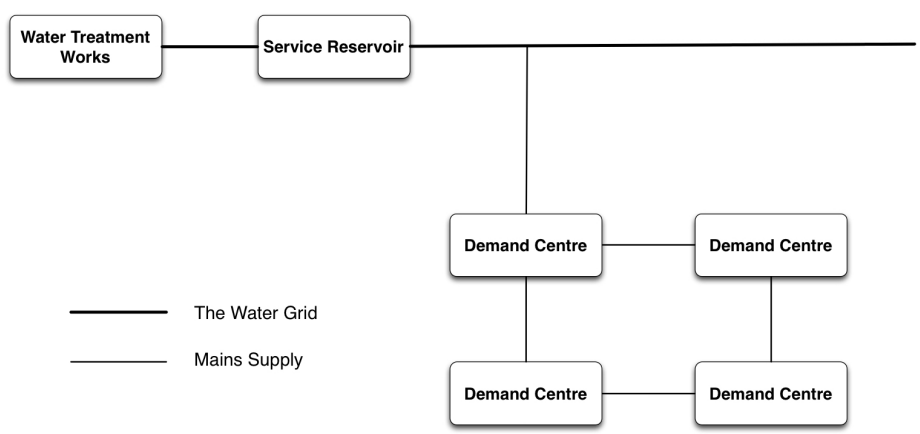

Figure 4. Single Mains Supply to Demand Centres

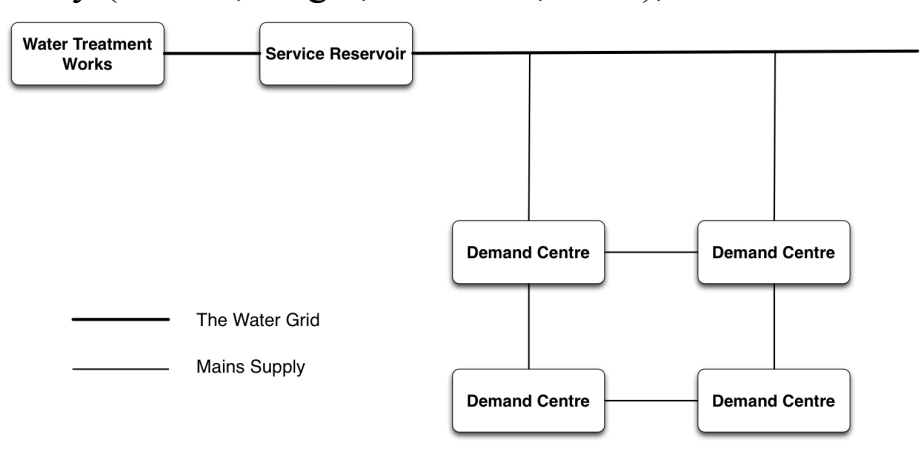

Figure 5. Dual Mains Supply to Demand Centres

\section{Systems of Systems and Reference Architecture}

The reference architecture of a SoS portrays the existing, current SoS architecture of the operational system. Figure 6 illustrates a design space exploration process for a generic SoS with a range of internal and external forces pushing for a changing set of requirements of the system; meaning updates to the SoS are needed. Some examples of external forces on our case study of the water supply system in the UK include; an increase in demand for different types of consumers (household, industry, agricultural); regulations imposed on water companies to reduce water abstraction, and; climate change. Similarly, for internal forces, these may include factors such as new available technologies and new enterprise goals by individual water companies. This illustration was produced as part of on-going research looking at a framework for architecting resilience in SoS at the early conceptual, design phases.

The outcome of the architecture modelling process represents the architectural variants that have the potential to meet most, if not all, the new requirements of the SoS. Where no single architecture variant fully meets the requirement, there is the possibility that several of the candidate architectures could nearly meet the requirement but with different performance levels. However, at this stage factors such as cost, system performance, availability, resilience etc. have not been traded against each other to identify optimal solutions. Therefore, provision must be made to allow the strongest candidate architectures to be considered during analysis of the SoS and evaluated against the SoS and CS goals, to determine which solutions are most feasible and lie along the pareto front. 


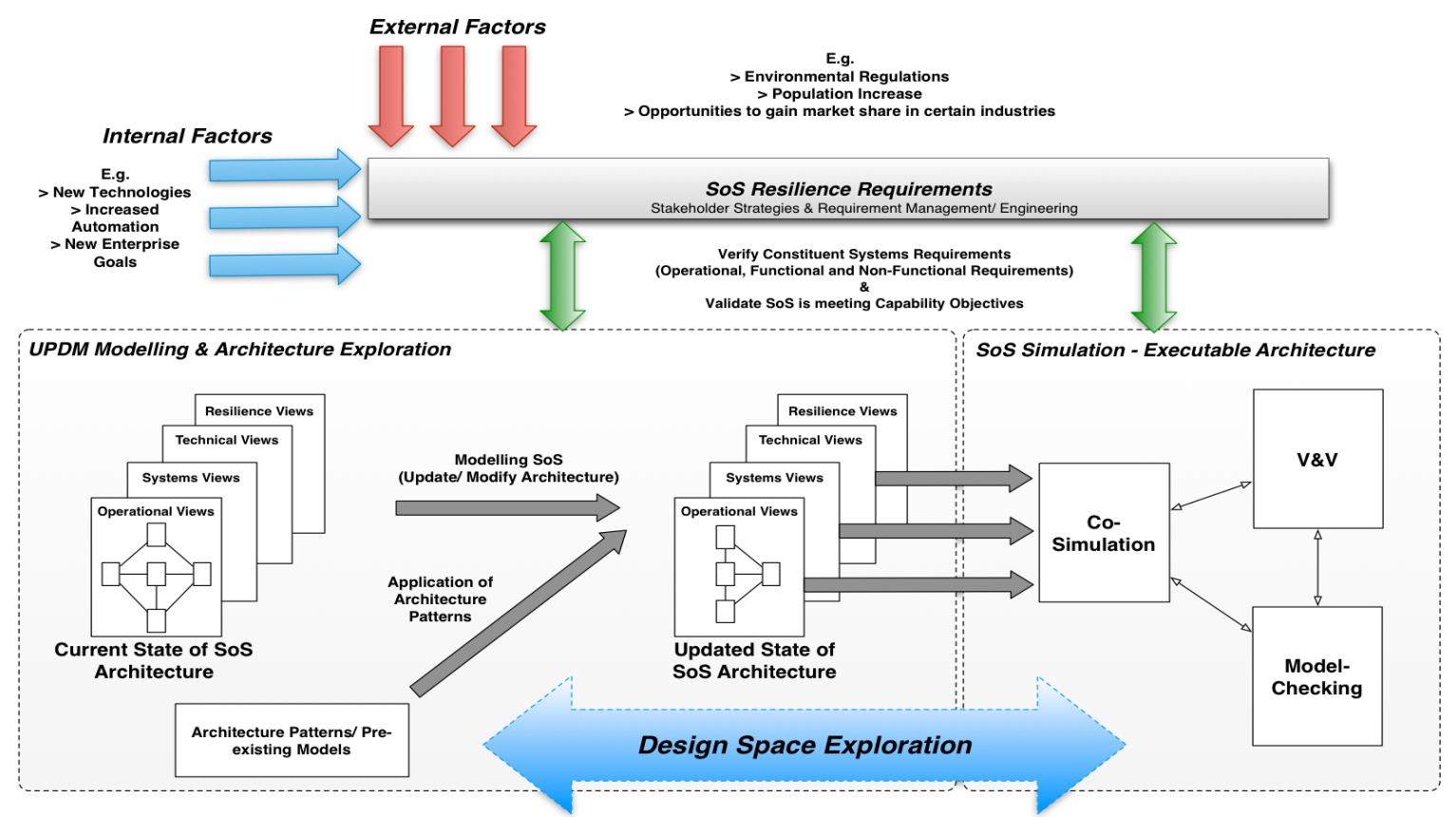

Figure 6. SoS Architecture Modelling and Design Space Exploration Process

The role of the resilience viewpoint is also highlighted in Figure 6 where it is applied along-side other views in UPDM that allows the architect to fully describe the current state of the SoS. Furthermore, this also permits future state modelling of architectural variants that provide the desired additional capability. The resilience viewpoint is necessary at both stages, to assess current resilience of the SoS topology and to explore future resilience strategies through systems modeling. As with all modeling endeavours, the end goal is to simulate models to analyse their behavior and to validate the model against real data. The figure shows the process of creating the models and then submitting them to a co-simulation environment to assess the performance metrics which have been defined within the architecture. Although the role of the resilience viewpoint is static, it is a stepping-stone to the end goal of completely executable architectures. This article is primarily focused around the idea of this novel viewpoint and the benefits it will give to the architect in the case of engineering future states of SoS. It does not suggest the processes for translating static models into executable models in specific environments, although the emerging FMI standard (Blochwitz et al., 2009) is working towards achieving this.

\section{The Need for a Resilience Viewpoint}

An architecture framework is defined by ISO/IEC/IEEE 42010 as, "conventions, principles and practices for the description of architectures established within a specific domain of application and/or community of stakeholders" (42010, 2016). Architecture frameworks assist architects or system developers in developing a model using some predefined guidelines. It provides a set of views that allow the systems architect to model a specific set of requirements by providing a systematic approach in understanding what aspects of a system would be relevant for a particular SoS, constituent system, or a stakeholder. Providing a certain set of perspectives called views that represent different aspects of a system the engineer can adopt and apply it in a manner that best fulfils its requirement. Architecture frameworks are useful because they provide:

- A standard and systematic thought structure

- A set of standard views and view descriptions

- A standard data structure to retain and relate information

- A standard approach to develop architectures (Urbaczewski \& Mrdalj, 2006) 
Architecture frameworks were created to offer a guideline for developing architectures. The most commonly used frameworks are Zachmann and ToGAF, DoDAF, MoDAF (Hause, 2010a; Rouhani, Mahrin, Nikpay, Ahmad, \& Nikfard, 2015; Urbaczewski \& Mrdalj, 2006). Although these frameworks are commonly being used, each was developed for a purpose and is consequently specific to a particular domain. Each framework compromises a given set of views, however being domain specific these frameworks are most suitable to be used in the domain they were developed for. Architecture Frameworks have been characterized into four types based on the domains that they are used in: SoS, systems, enterprise and software architectures (Erol \& Sauser, 2009). The first framework to support systems thinking was the Zachmann framework (Urbaczewski \& Mrdalj, 2006). The likes of DoDAF and MoDAF were developed for military purposes in the US Military and the UK military, respectively.

Architecture frameworks support various methodologies to address the complexity of SoS. Although Architecture frameworks enable standardised modeling for any SoS, they have limited capabilities when it comes to lifecycle development of a SoS (Rouhani et al., 2015). Unfortunately, none of the architecture frameworks have simulation, verification and validation capabilities, which are undeniably essential to explore SoS and the resilience of SoS. As evolution is an important feature of a SoS, any SoS model needs to be able to allow architecture evolution. Furthermore, modeling human factors in SoS using these frameworks has always been argued and no particular architecture framework or any methodology describes a set method for incorporating human factors into modeling. The human aspect of SoS is crucial in the resilience and reliability of operational systems, and it is proposed to include a human element view within the resilience viewpoint. With changes in modeling methodologies and continuous evolution of SoS it has become essential that human factors be given more weight age while modelling SoS. The lacking capabilities of architecture frameworks can be summarised as follows:

- Architecture frameworks do not indicate how to model humans or human behavior in a system.

- Architecture frameworks do not have an extensive simulation capability.

- Architecture frameworks do not permit the modeling of resilience aspects of systems/ SoS.

- Architecture frameworks do not have optimization capability.

- Architecture frameworks do not allow system verification and validation.

The development of a "Resilience Viewpoint" within an Architectural Framework like DoDAF, MoDAF or the UPDM modelling language(Urbaczewski and Mrdalj, 2006;) has stemmed from extensive review and practical application of architecture frameworks in several industrial projects (DANSE, 2014). The benefits of exercising an architecture during systems engineering projects is highly detailed in literature that covers an assortment of domains and in different contexts; autonomous ground transport (Winokur, Dov, \& Kemper, 2013); air transport systems ("Airbus," 2017; Winokur et al., 2013); military and defence; water supply (Winokur et al., 2013); enterprise organisations. Frameworks such as DoDAF and MoDAF support the following functions:

- Modeling architectures for complex systems that include hardware, software, data, personnel and facility elements.

- Modeling of systems of systems from high-levels of abstraction to the lower levels of detail.

- Enhance the architecture information exchange among UML/SysML based tools.

UPDM models can be combined with Constituent System (CS) models to create a joint time-based simulation of the SoS - This simulation allows evaluation of emergent behavior, discover any unpredicted emergent behaviors (potentially resilience), predict performance and find errors in the analysis. 


\section{The Proposed Resilience Viewpoint}

The proposed viewpoint (Figure 7) will have views contained within, and will be an addition to existing architecture frameworks, such as DoDAF (Figure 8). The inclusive views will be applied to conduct analysis, such as static structural analysis (Filippini \& Silva, 2014) of the resilience of a collection of systems. The semantics and the tools associated within the specific models will be suggested as those required to generate the models needed. For example, the tools will have 'connections' such as "vulnerable" and "critical" to define the relationships between the CS and nodes of the network.

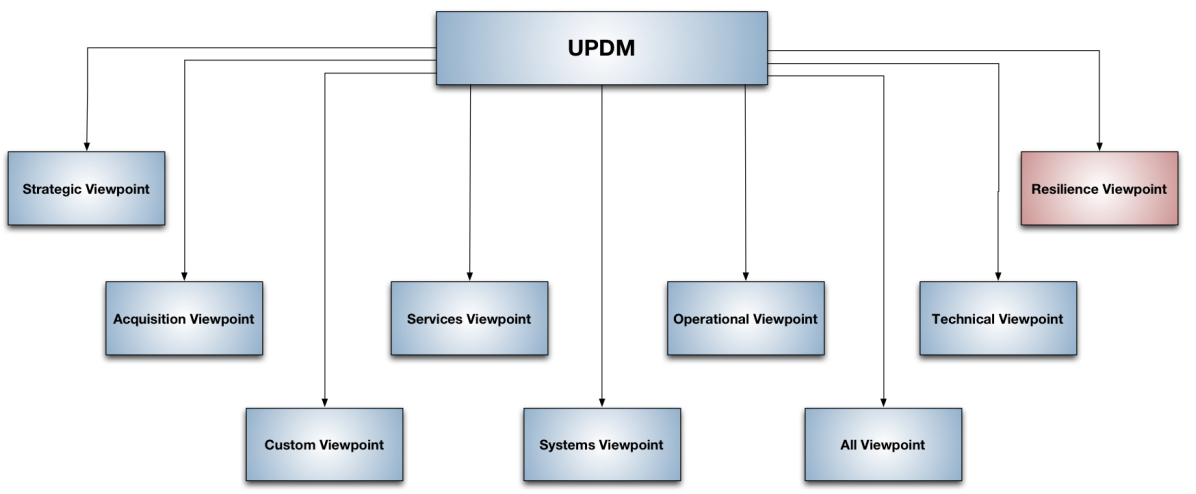

Figure 7. Resilience Viewpoint in DoDAF, MoDAF and UPDM

UPDM is a modeling language that consists of a set of viewpoints derived from both DODAF and MODAF. Details of what the different viewpoints offer from a modelling perspective can be found in (Hause, 2010a, 2010b; OMG, 2013), therefore we will not discuss these at length but introduce a summary description of the proposed Resilience Viewpoint;

Resilience Viewpoint: The Resilience Viewpoint is a technical viewpoint that describes interactions amongst constituent systems and provides details of interaction types and particulars about vulnerability and criticality aspects of constituent elements. Additionally, the viewpoint is to be developed to include constraints and requirements from a resilience standpoint, showing the redundancy and common-mode failure aspects in designs.

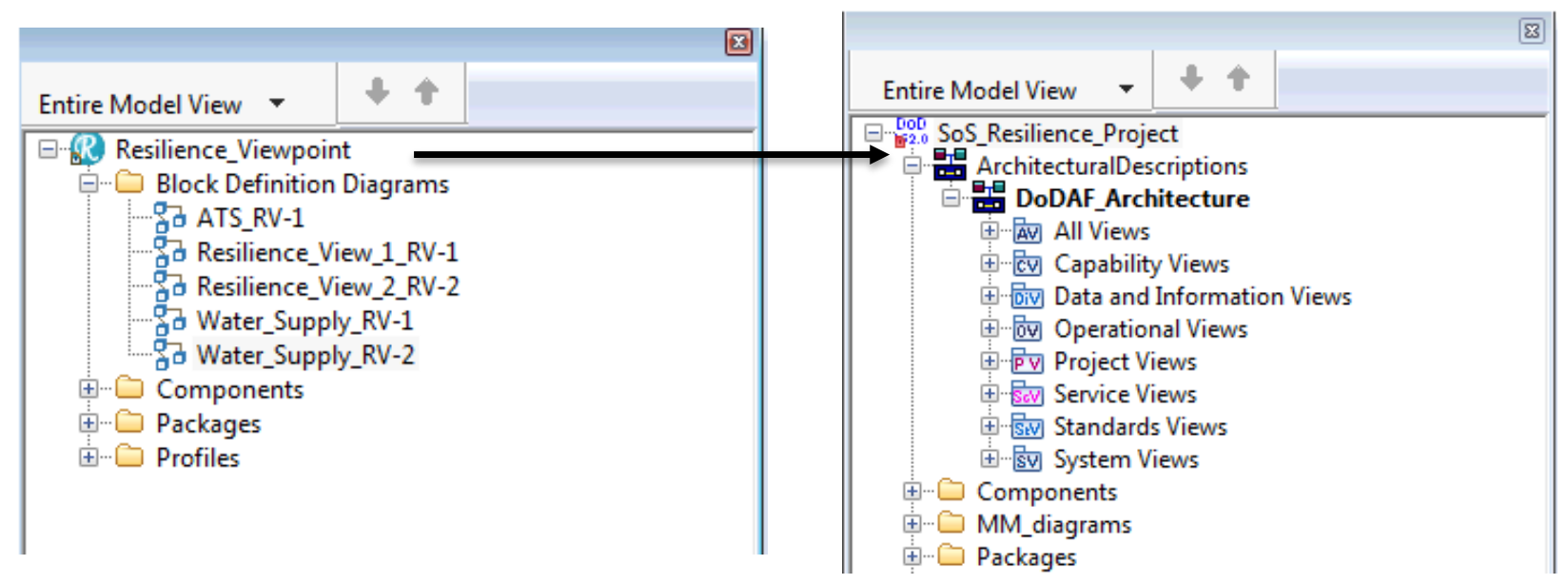

Figure 8. Resilience View Package to be Included with Existing Viewpoint Packages

The initial view within the RV, RV-1 shows the high-level integration of constituent systems and their dependencies, communication and information channels and general operational relationships. This view will be similar to an operational view 1, OV-1 and systems view 1, SV-1 combined. The benefit of having a view which includes both sets of information, is that the detail can be fleshed out 
in greater detail in a single instance, giving the architect more transparency of the operational aspects of the constituents. Furthermore, it allows for better understanding, operationally, illuminating areas of weakness within the SoS topology. This view precedes Resilience View 2, RV-2, a view analysing the structural resilience of the CS's of interest. A generic example is provided for both RV-1 and RV2 in Figures 9 and 10, respectively. Figure 9 shows both the dependencies with a 'Dependency' connector and the information/data flows with a 'Flow' connector, connecting ports assigned to individual blocks/ CS.

Resilience View 2, RV-2 allows the architect to depict the 'criticality' and 'vulnerability' within the topology. This is thought to be useful in applying a method that has been adopted from (Filippini \& Silva, 2014) that shows the static resilience of critical infrastructure systems and SoS. This method can be applied to SoS from domains outside critical infrastructure, and by permitting such analysis within an architecture framework; it sanctions greater resilience understanding of the SoS for the architect who is attempting to design additional resilience features. By doing so, different architectural variations, i.e. different CS topologies, different structural components can be tested and evaluated within such a design space. As seen in figure 6, design space exploration must satisfy most, if not all, SoS goals, therefore architecture variants must not just make sense structurally; they must still deliver the dynamic attributes and performance metrics specified by the requirements. It is not always possible to meet every performance factor; it is essential to select the optimal candidate architectures to further analyse in perspective of the SoS requirements.

bdd [Project] Resilience_Viewpoint [Resilience_View_1_RV-1]

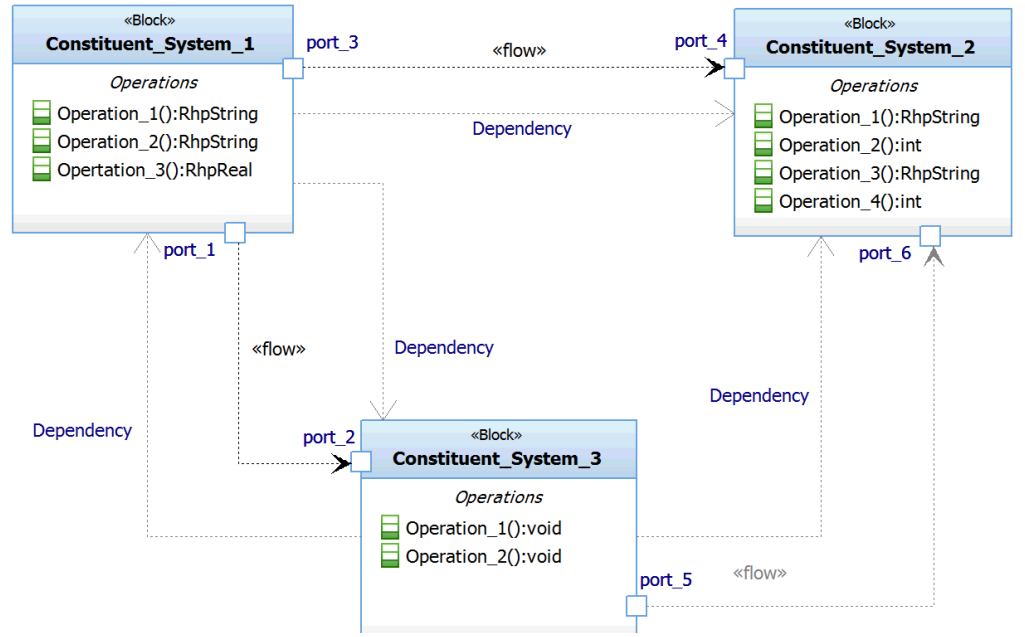

Figure 9. Generic Resilience View 1 (RV-1) Model

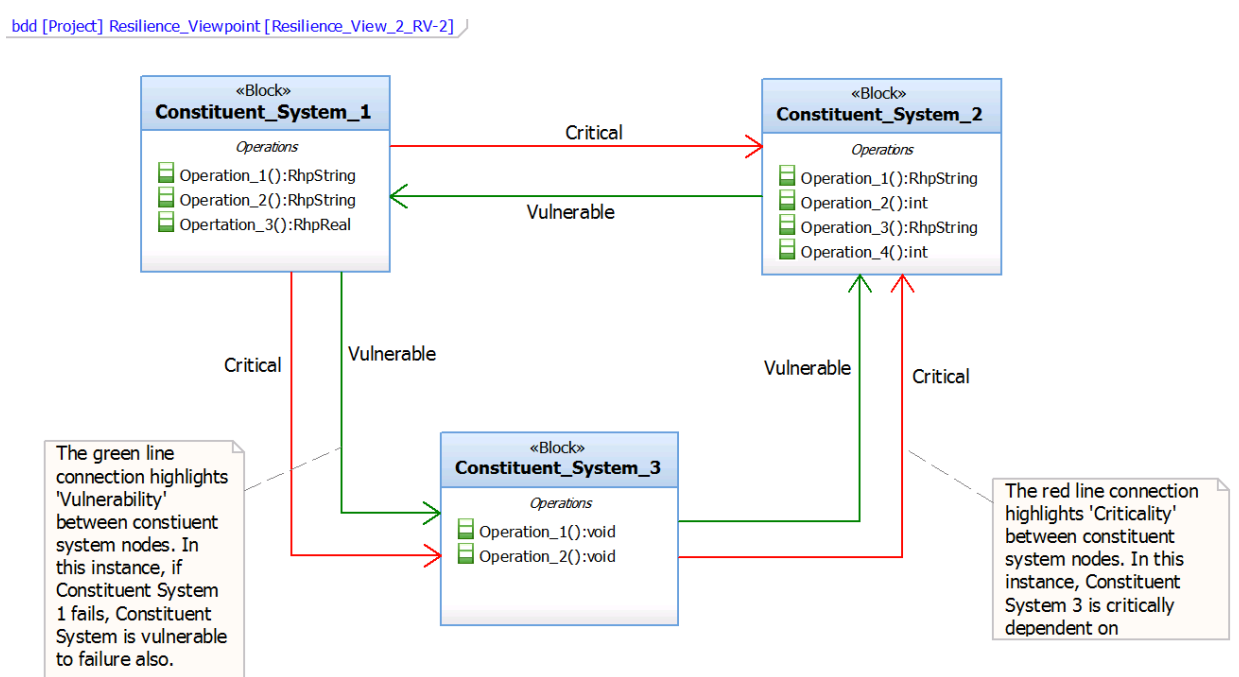

Figure 10. Generic Resilience View 2 (RV-2) Model (Annotated) 


\section{Resilience Viewpoint Applied to Water Supply SoS}

The work described in this paper will now be exemplified through the water supply case study and demonstrated to better portray the application of the resilience viewpoint.

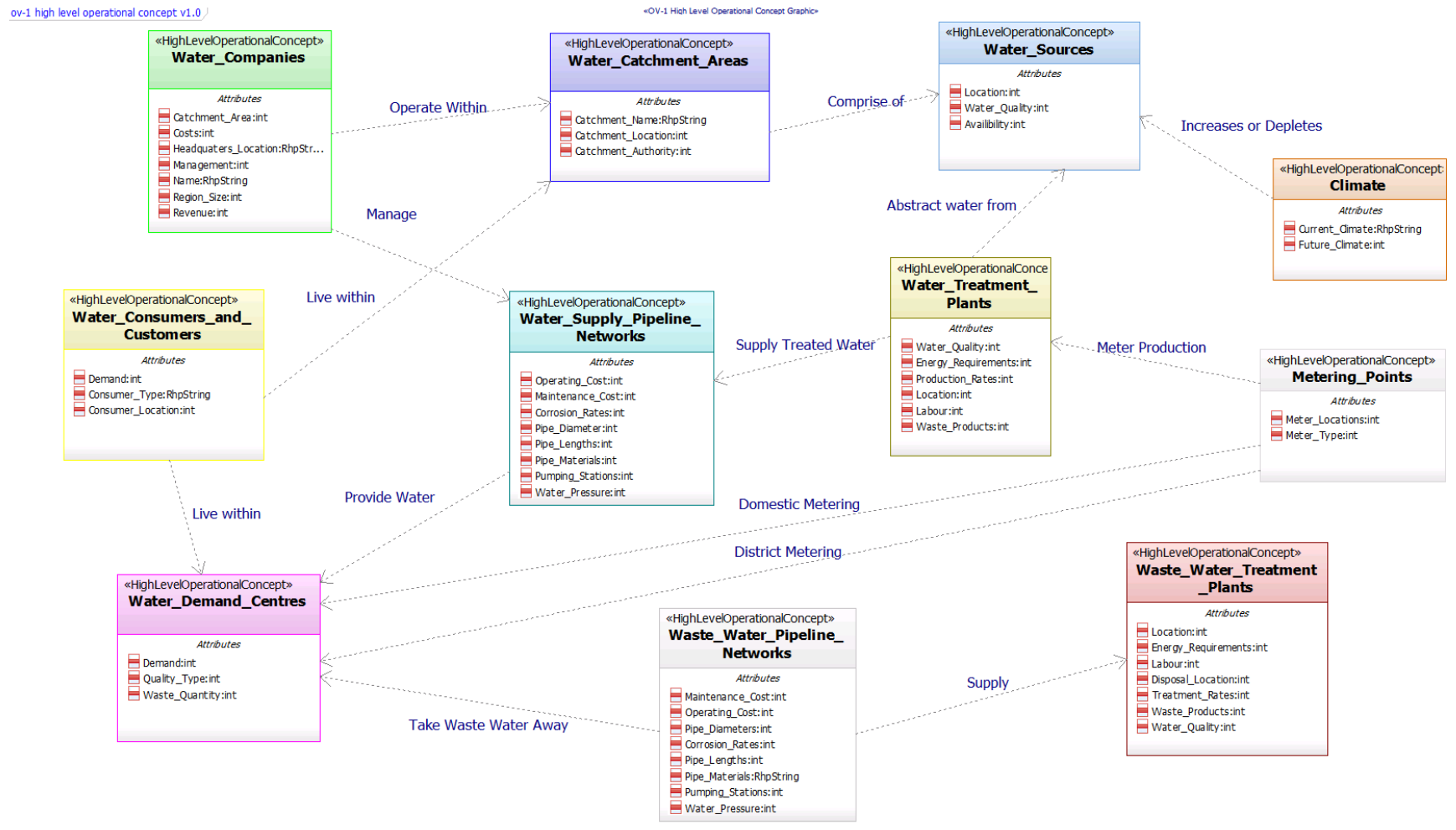

Figure 11. UPDM Operational View $1(\mathrm{OV}-1)$ Model of Water Supply SoS

The future availability of water in the UK is uncertain. Projections (UKP09) suggest that the change in climate and the rise in demand for water will increase pressure on current water resources. General trend projections indicate warmer and drier summers that will result in less water being available for all uses in the coming decades. Also, of concern are drier winters (draught), which results in the water resources (e.g. reservoirs and ground water sources) becoming depleted and not adequately replenishing before the spring and summer seasons, resultantly, putting substantial pressure on the water resources during summer months. It is suggested by the Environment Agency (EA) that some water resources in England and Wales are already under extreme pressure and are becoming unsustainable (Knight, Bishop, Grimshaw, Hughes, \& Franks, 2016). This is an issue because there are no additional water resources to meet and fulfil the increasing demands of society, commerce and industry. To the end, the water needs of the UK population, industry and associated dependencies are expected to increase due to population growth (Knight et al., 2016), and thus, a resilient and robust water supply system is required for the forthcoming years and decades.

Prior to exploring new water management strategies and solutions to meet the problems described in the water supply context, good systems engineering practice seeks to effectively engage stakeholders. Figure 11 outlines an initial stakeholder relationship map of the water supply system that shows the interdependencies within an OV-1 model in UPDM. Furthermore, to carry out "problem structuring methods" (Stillitto, 2015), a suggested method of causal loop modeling are employed to share, express and explain the problem to stakeholders. The importance of stakeholder engagement in any SoS project cannot be overstated. Engaging with stakeholders from different backgrounds and domains is crucial in understanding how they perceive the problem, or what their expectations are from a potential development or solution. Adapting a sound stakeholder strategy is an important facet to have early on, hence why creating an OV-1 (Figure 11) was strongly advised in the architecture 
development phase, so that the intricacies amongst stakeholders are understood, thus providing a good basis which the SoSE can teeth the nuances out of potentially biased stakeholder views. Stakeholder views will typically be centered at the CS-level and will likely be based on subjective experience that might not be completely relevant to the given problem or the new proposition.

There is therefore an evident requirement for resilient in the water supply system within the UK. This resilience would imply that water is successfully supplied to all demand regions (domestic, industrial and agricultural) whatever the circumstances are of the environment. The causal loop in Figure 12 shows the demand centres with respect to the rest of the water supply SoS. It can be seen from the figure, that the ever-increasing population puts pressure on providing water at a higher volume, this in itself requires thoughtful planning and alternative architectural solutions to meet this requirement. Additionally, the causal loop entails both the scenario of less water availability and increase temperatures, and also in crisis scenarios such as natural and made-made disasters. Natural disasters increase the probability of the water infrastructure being damaged and could jeopardize the supply of water (possibly clean drinking water) to customers. The concept of resilience, as discussed before, would attempt to mitigate against this risk and ensure the availability of water is present, even in times of severe circumstances, e.g. draught, floods, earthquakes and other scenarios.

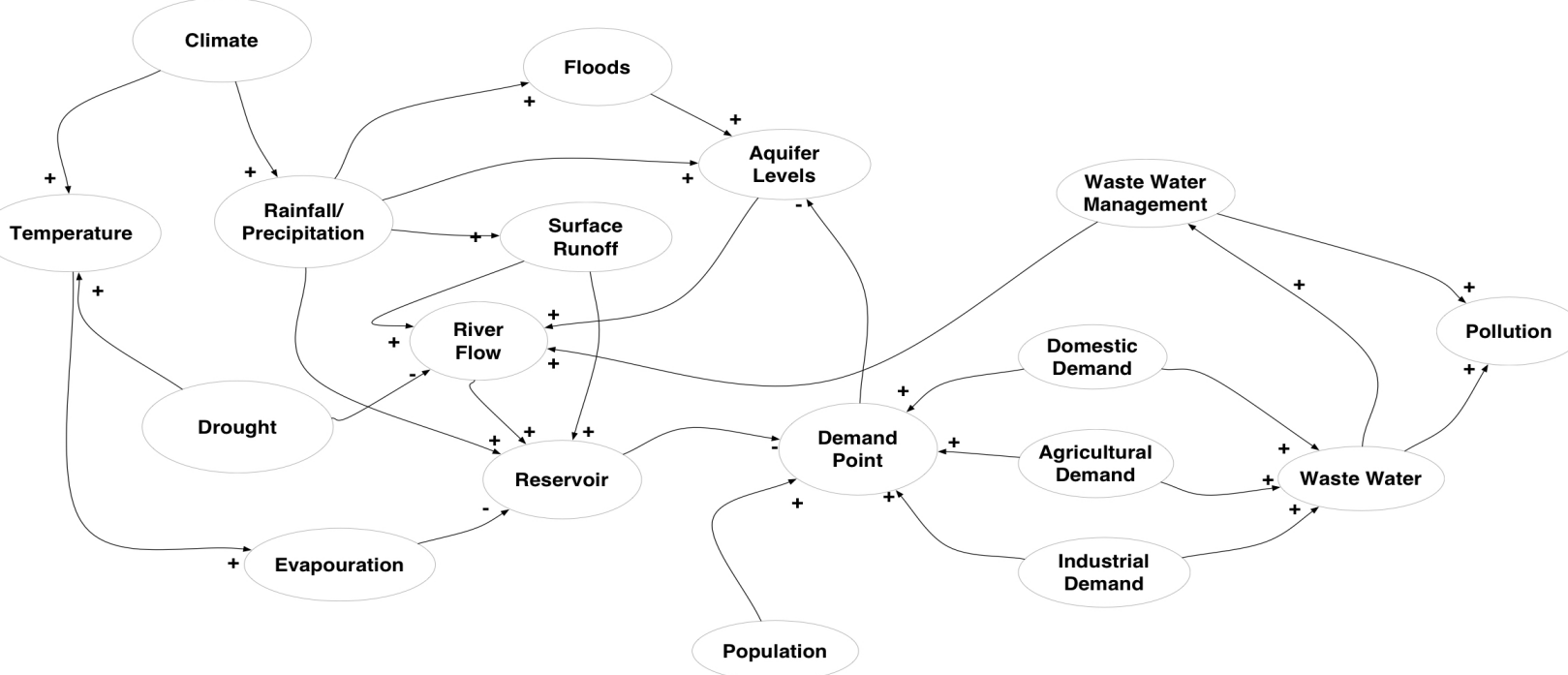

Figure 12. Causal Loop Diagram of Water Supply SoS

RV-1 in Figure 13 shows the dependency between three elements of the water supply SoS; the water treatment works; a clean water distribution network, and; water demand centres. The model allows the architect to model the operations of the CS and the dependencies and flows of information, data or resources between the elements as discussed previously. A subset of operations of the distribution network may include flow direction (displacement), flow rate $\left(\mathrm{m}^{3} / \mathrm{s}\right)$, capacity $\left(\mathrm{m}^{3} / \mathrm{s}\right)$, and pipe dimensions (m). Having created this top-level model, the RV-2 model can be applied to build the resilience picture and provide more insights into the problem space.

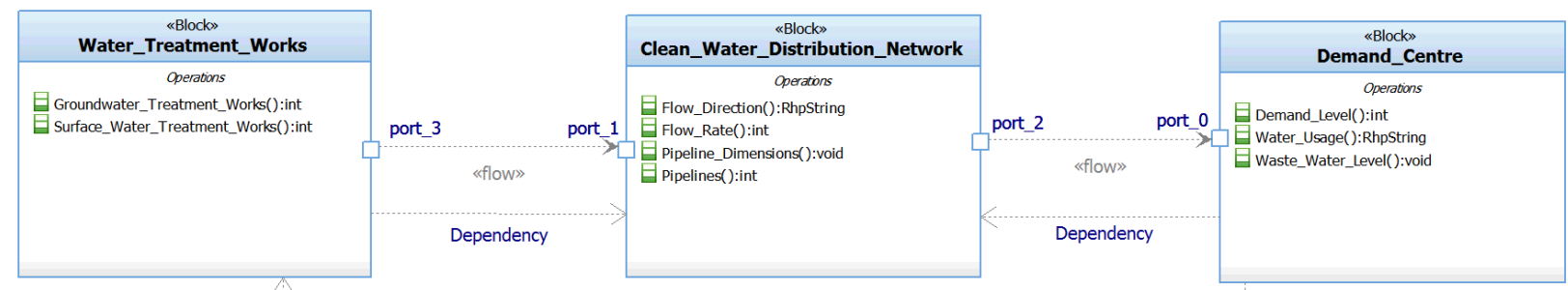

Figure 13. Example RV-1 Model of Water Supply SoS 
The next phase of the proposed modelling process is to identify the vulnerable elements of the network and those that are critically dependent on other elements. The RV-2 model in Figure 14 highlights that the demand centres, as expected are critically dependent on the mains supply pipes to deliver fresh potable water to them and if the existing infrastructure (pipes) were to be damaged by some means, they become unstuck and without clean water. This may seem an obvious point to make, however by understanding the current system to great detail, fail-safe mechanisms can be implemented at the local level to alleviate against potential threats. This is clearly true for all types of systems, not only SoS. The important point to take from the RV-2 is that it has the capability to define 'critical' relationships and also 'vulnerable' elements within the topology. A standalone demand centre, which may be a small rural community, may be vulnerable if they have only one source of water. A future design could be to connect that community's water network to another demand centre and if required, to conduct water sharing between two demand centres. The infrastructure has a monetary cost; however, the level of resilience would have increased, especially for that individual demand centre.

Significantly, the level of abstraction plays an important role in modeling systems such as the water supply SoS, and in the above example, lower levels of details can be modeled in separate instances of the proposed viewpoints. Detailed models may include specifics of the water supply infrastructure and incorporate pipe types, pumping stations, local reservoirs and so forth. Additionally, it is anticipated further resilience viewpoints will be developed to include non-functional aspects (ilities') (Ricci, Fitzgerald, Ross, \& Rhodes, 2014) which are believed to be an important approach to architecting resilient SoS. Such a viewpoint is currently under development and will allow the architect to highlight areas of where properties like flexibility, adaptability and changeability are lacking, and the possibility to design these properties into the architecture.

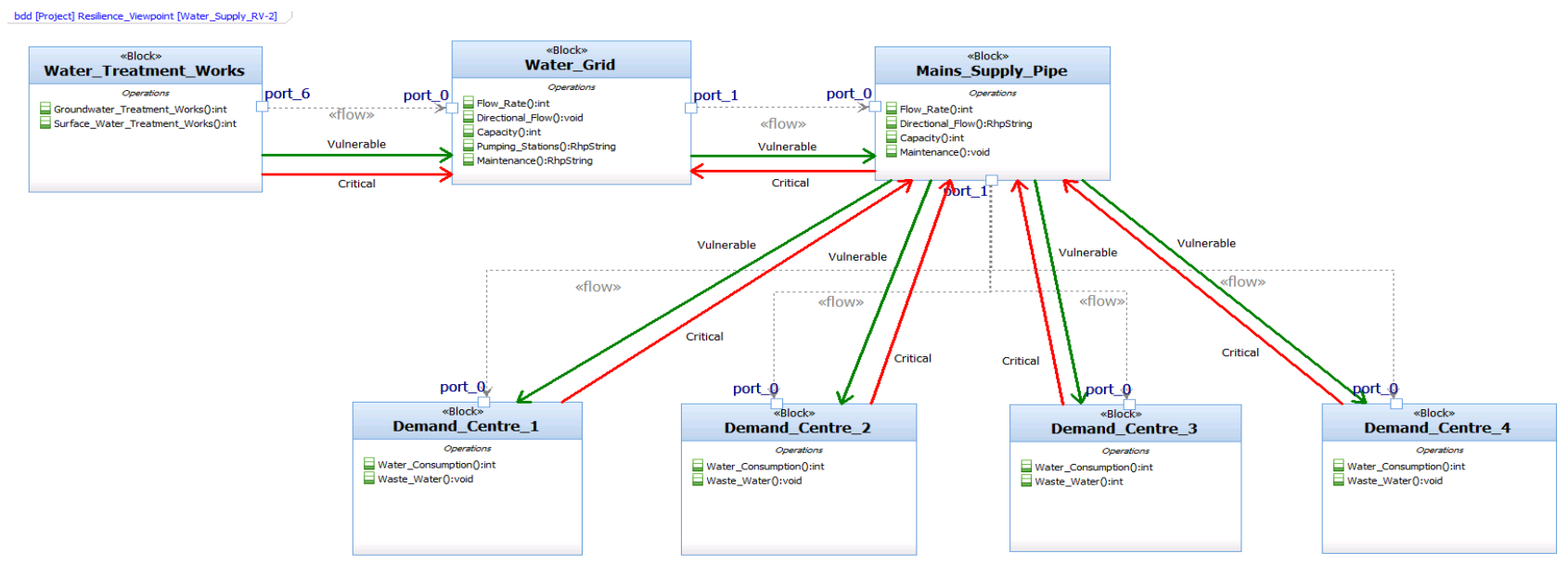

Figure 14. Example RV-2 Model of Water Supply SoS

Coincidentally, this viewpoint will seamlessly follow current architecture modeling methodologies and can be seen to flow coherently on from views from both the operational view package and the systems view package. Having defined the operational aspects of the system the concept of operations (CONOPS) using a series of operational views, the resilience aspects can be explored further, assigning functions to specific systems within the relevant views, within the systems view package. The architect can systematically and iteratively explore the resilience aspects of the systems of interest (SOI) by applying the proposed viewpoints.

\section{Conclusion}

This paper has proposed a novel architecture viewpoint to be developed within the existing architecture frameworks DoDAF, MoDAF and the Unified Profile of DoDAF and MoDAF (UPDM) modeling language, to tackle aspects of resilience - the Resilience Viewpoint. The viewpoint is an on- 
going work-in-progress development, which forms part of a $\mathrm{PhD}$ research project aimed developing a framework for architecting resilience in systems of systems (SoS) at the early phases of design. The viewpoint is to be utilised by systems engineering practitioners and systems architects in both industry and academia with an interest in systems modeling and aspects of resilience engineering. This paper has proposed two views; Resilience View 1 (RV-1) and Resilience View 2 (RV-2), which offer semantics above and beyond those of currently existing views, namely, dependency and flow relationships, and vulnerability and criticality aspects between constituent systems, respectively. The research is focussed on further developing these two views, along with potentially introducing another view that offers the architect the capability to architect ilities (e.g. adaptability, , flexibility) into the SoS and its CS. Ultimately, this work will demonstrate how it will be possible to take an architecture, and demonstrate its performance qualities through some form of executable forms of the generated models within the resilience viewpoint and the architecture framework, as a whole.

\section{References}

42010, I. (2016). Systems and software engineering - Architecture Description ISO/IEC/IEEE 42010. Retrieved September 30, 2017, from http://www.iso-architecture.org/ieee-1471/afs/

Airbus. (2017). Retrieved September 26, 2017, from http://www.airbus.com/

Ash, J., \& Newth, D. (2007). Optimizing complex networks for resilience against cascading failure. Physica A: Statistical Mechanics and Its Applications, 380(1-2), 673-683. https://doi.org/10.1016/j.physa.2006.12.058

Bergström, J., Winsen, R. Van, \& Henriqson, E. (2015). On the rationale of resilience in the domain of safety: A literature review. Reliability Engineering and System Safety, 1-11. https://doi.org/10.1016/j.ress.2015.03.008

Bernice Lee, Felix Preston, \& Gemma Green. (2012). Preparing for High-impact, Low-probability Events: Lessons from Eyjafjallajökull, 1-62. https://doi.org/ISBN 9781862032538

Blochwitz, T., Otter, M., Arnold, M., Bausch, C., Clauß, C., Elmqvist, H., ... Wolf, S. (2009). The Functional Mockup Interface for Tool independent Exchange of Simulation Models. 8th International Modelica Conference 2011, 173-184. https://doi.org/10.3384/ecp12076173

Bullock, S., \& Cliff, D. (2005). Complexity and emergent behaviour in ICT. Foresight project web site.

Christopher P. Nemeth, E. H. (2014). Resilience Engineering in Practice: Becoming Resilient (Volume 2). Ashgate.

DANSE - Designing for Adaptability and evolutioN in System of systems Engineering. (2014). Retrieved from http://danse-ip.eu/home/

Erol, O., \& Sauser, B. (2009). A Framework for Enterprise Resilience Using Service Oriented Architecture Approach.

Filippini, R., \& Silva, A. (2014). A modeling framework for the resilience analysis of networked systems-of-systems based on functional dependencies. Reliability Engineering and System Safety, 125, 82-91. https://doi.org/10.1016/j.ress.2013.09.010

Friedenthal, S., Moore, A., \& Steiner, R. (2014). A Practical Guide to SysML - The Systems Modeling Language (3rd Editio). Morgan Kaufmann.

Hause, M. (2010a). The unified profile for DoDAF/MODAF (UPDM) enabling systems of systems on many levels. 2010 IEEE International Systems Conference Proceedings, SysCon 2010, 426431. https://doi.org/10.1109/SYSTEMS.2010.5482450

Hause, M. (2010b). The Unified Profile for DoDAF/MODAF (UPDM) enabling systems of systems on many levels. 2010 IEEE International Systems Conference, 426-431. https://doi.org/10.1109/SYSTEMS.2010.5482450

Hayden, J. L., \& Jeffries, A. (2012). On using SysML, DoDAF 2.0 and UPDM to model the architecture for the NOAA's Joint Polar Satellite System (JPSS) Ground System (GS). 12th International Conference on Space Operations, SpaceOps 2012, 1-13. https://doi.org/10.2514/6.2012-1289592

Hessami, A. G. (2011). System of Systems and Emergence. https://doi.org/10.1109/ICETET.2011.51 
Hessami, A., \& Karcanias, N. (2010). Systems Assurance, Complexity and Emergence: The Need for a Systems Based Approach. In S. Tenreiro de Magalhães, H. Jahankhani, \& A. Hessami (Eds.), Global Security, Safety, and Sustainability SE - 22 (Vol. 92, pp. 202-215). Springer Berlin Heidelberg. https://doi.org/10.1007/978-3-642-15717-2_22

Hollnagel, E., Paries, J., Woods, D. D., \& Wreathall, J. (2011). Resilience Engineering in Practice: A Guidebook. Ashgate Publishing Limited.

Hosseini, S., Barker, K., \& Ramirez-Marquez, J. E. (2016). A review of definitions and measures of system resilience. Reliability Engineering and System Safety, 145, 47-61. https://doi.org/10.1016/j.ress.2015.08.006

Hou, M., Banbury, S., \& Burns, C. (2014). Intelligent Adaptive Systems - An Interaction-Centred Design Perspective. CRC Press.

Ibarra-zannatha, J. M., Limón, R. C., Hernandez, W. E. C., Electronico, I., Estefan, J. A., Obaidat, M. S., ... Kosbar, K. L. (1994). Survey of Model-Based Systems Engineering ( MBSE ) Methodologies 2 . Differentiating Methodologies from Processes, Methods, and Lifecycle Models. Environment, 32(7), 397-438. https://doi.org/10.1109/35.295942

Karcanias, N., \& Hessami, A. G. (2011). System of systems and emergence Part 1: Principles and framework. In International Conference on Emerging Trends in Engineering and Technology, ICETET (pp. 27-32). https://doi.org/10.1109/ICETET.2011.51

Knight, C., Bishop, T., Grimshaw, M., Hughes, S., \& Franks, L. (2016). Water resources long term planning framework (2015 - 2065).

Labaka, L., Hernantes, J., \& Sarriegi, J. M. (2015). Resilience framework for critical infrastructures: An empirical study in a nuclear plant. Reliability Engineering and System Safety, 141, 92-105. https://doi.org/10.1016/j.ress.2015.03.009

Madni, A. M., \& Jackson, S. (2009). Towards a Conceptual Framework for Resilience Engineering, $3(2), 181-191$.

Maier, M. W. (1996). Architecting Principles for Systems-of-Systems. INCOSE International Symposium, 6(1), 565-573. https://doi.org/10.1002/j.2334-5837.1996.tb02054.x

McManus, H., Richards, M. G., Ross, A., \& Hastings, D. (2007). A Framework for Incorporating "ilities" in Tradespace Studies. American Institute of Aeronautics and Astronautics, (Conference and Exposition), 1-14. https://doi.org/10.2514/6.2007-6100

Mohammad, M., Kaminskiy, M., \& Krivtsov, V. (2010). Reliability Engineering and Risk Analysis. (T. \& F. Group, Ed.) (Second Edi). CRC Press.

Nelson, D. R., Adger, W. N., \& Brown, K. (2007). Adaptation to Environmental Change: Contributions of a Resilience Framework. Annual Review of Environment and Resources, 32, 395-419. https://doi.org/10.1146/annurev.energy.32.051807.090348

OMG. (2013). Unified Profile for the Department of Defense Architecture Framework (DoDAF) and the Ministry of Defence Architecture Framework (MODAF). Retrieved from http://www.omg.org/spec/UPDM/

Ota, D., \& Gerz, M. (2011). Benefits and Challenges of Architecture Frameworks. Sixteenth International Command and Control Research and Technology Symposium.

Oxford Dictionary of English. (2010). OXFORD University Press. https://doi.org/10.1093/acref/9780199571123.001.0001

Rahimi, M., \& Madni, A. M. (2014). Toward a resilience framework for sustainable engineered systems. Procedia Computer Science, 28(Cser), 809-817. https://doi.org/10.1016/j.procs.2014.03.096

Ricci, N., Fitzgerald, M. E., Ross, A. M., \& Rhodes, D. H. (2014). Architecting systems of systems with ilities: An overview of the SAI method. In Procedia Computer Science (Vol. 28, pp. 322 331). https://doi.org/10.1016/j.procs.2014.03.040

Rouhani, B. D., Mahrin, M. N., Nikpay, F., Ahmad, R. B., \& Nikfard, P. (2015). A systematic literature review on enterprise architecture implementation methodologies. Information and Software Technology, 62, 1-20. https://doi.org/10.1016/j.infsof.2015.01.012

Stillitto, H. (2015). Architecting Systems - Concepts, Principles and Practice. (C. Publications, Ed.) 
(Vol.

$6)$.

printondemand-worldwide.com.

Retrieved

from

http://suprimo.lib.strath.ac.uk/primo library

Uday, P., \& Marais, K. B. (2014). Resilience-based system importance measures for system-ofsystems. In Procedia Computer Science (Vol. 28, pp. 257-264). Elsevier Masson SAS. https://doi.org/10.1016/j.procs.2014.03.033

Urbaczewski, L., \& Mrdalj, S. (2006). A comparison of enterprise architecture frameworks. Issues in Information Systems, 7(2), 18-23. https://doi.org/10.1227/01.neu.0000410082.42657.aa Winokur, M., Dov, N. Ben, \& Kemper, S. (2013). DANSE Methdologody: Deliverable D_4.4.

\section{Biography}

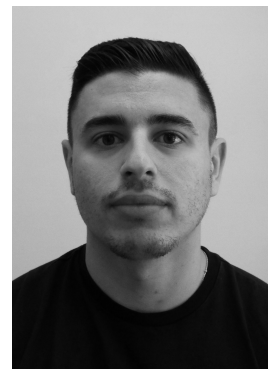

D. Joannou received his B.Eng. degree in Systems Engineering from Loughborough University, UK, in 2011 and is currently pursuing a Ph.D. degree in Systems Engineering, specifically focusing on engineering resilience into Systemsof-Systems. His role as a Research Associate for the past four years has seen him working on large collaborative EU FP7 and Innovate UK and Airbus funded projects looking at advanced modelling and simulation methods through the application of architecture frameworks and a range of other systems modelling languages. His research interests include; systems-of-systems and system complexity; system modelling techniques and architectural frameworks; and engineering resilience and emergent behaviours.

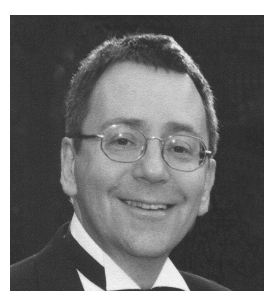

Prof. R. S. Kalawsky (PhD (Hull 1991), MSc (Hull 1984), BSc (Hull 1978), C.Eng, FIET, FRSA) is Director of the Advanced VR Research Centre in the Wolfson School of Mechanical, Electrical and Manufacturing Engineering at Loughborough University, UK. He has extensive industrial and academic experience in systems engineering spanning over 32 years. He spent over 17 years working for BAE Systems and was responsible for Advanced Crew Station research across the Military Aircraft Division. He joined Loughborough University in 1995 and established the Advanced VR Research Centre to specialize in advanced systems, modelling and simulation, synthetic environments and advanced visual analytics. 